\title{
Linking Teaching and Training Methods: Classroom Teaching vis-a-vis Workplace Training within the Hospitality Industry
}

\author{
Lucy Ajambo $^{1}$, Leikny $\emptyset_{\text {grim }}^{2}$, Justine Nabaggala ${ }^{3}$ \\ ${ }^{\text {I }}$ Faculty of Educational Sciences for Teacher Education and International Studies, Oslo Metropolitan, University/ Kyambogo \\ University, Uganda \\ ${ }^{2}$ Faculty of Education and International Studies, Oslo Metropolitan University, Norway \\ ${ }^{3}$ Faculty of Vocational Studies, Kyambogo University, Uganda
}

\begin{abstract}
Harmonization of teaching and training methods (TTMs) continue be prerequisite and critical for teachers and trainers as they promote successful acquisition of essential and practical skills for further training in workplaces in Uganda. As the linkage is enfolded, it is confronted with increasingly distinctive challenges. This study aimed at exploring the linkage of TTMs between classroom teaching and workplace training in the hospitality industry in Uganda. A qualitative research approach using a case study design was used. A sample of 16 participants was purposively selected from vocational institutions and workplaces. In-depth interview were used to collect data. The study found out that the linkage of TTMs played a significant role in developing and strengthening of essential and practical competencies. Minimal participation, unsatisfactory use of teacher initiated methods, exhaustion and neglectful listening, unavailability, inadequate and obsolete tools, equipment and materials were also identified. The study recommends that TTMs in the hospitality industry should be allowed to evolve through a systematic harmonization, horizontal expertize and collaboration in order to have effective linkage of classroom teaching to workplace training that encourage and facilitate motivation, critical thinking and avail up-to-date tools, equipment and materials in vocational institutions
\end{abstract}

Keywords: teachers, trainers, teaching methods, training methods, harmonization, linkage, essential and practical competences

\section{INTRODUCTION}

$\mathrm{T}$ eaching and training methods (TTMs) as related to instruction in the hospitality industry [1], play a significant role in promoting active learning [2], successful acquisition of knowledge, skills, values, beliefs and habits[3], [4], fostering engagement and transformation [2]. They are also charged with a substantial function of nurturing essential and practical competencies for the hospitality industry[5], [6]. Additional advantages this relationship is the fostering of interactive environments, obtaining real-life, hands-on and industry-related competencies that are beneficial for the students successful transition for further learning [7], [8]. However, this linkage is confronted with challenges of harmonization in order to enable students' acquisition of essential and practical skills. [2]. Linking TTMs in vocational institutions and workplaces as a way of harmonizing and standardizing instruction due to its plausible role of improving and strengthening knowledge, skills and practices has therefore attracted a lot of attention. This therefore calls for an in-depth understanding of TTMs for both teachers in vocational institutions and trainers in the workplaces.

The advantage of such harmonization and collaboration of TTMs ensures effective horizontal expertize of classroom and workplace learning contexts. This horizontal expertize of teachers and trainers enables instruction arena and expansion to an adjacent functional arena in the same occupation[9]. Successively, [10] and [11] argued that regular curriculum reviews informed by up- to- date TTMs were found to adequately promote students' involvement in decision making in classrooms and workplaces. According to [12] and [13], there are striking shifts in educational delivery and strategy driven by external forces beyond the influence of educational institutions. These external forces that include growth of for-profit education and increased number of learning institutions have a significant impact on TTMs [12]. Teachers tend to use standard practices of classroom teaching that they usually take for granted [14], [15]. Such practices do not generate higher learning effectiveness to allow students to form their own learning experiences[3]. On the other hand, workplaces have used on the job training practices to re-train students undergoing internship[8] in order to strengthen the already acquired knowledge as well as interpersonal, problem solving and self-management skills[16]. Effective horizontal expertize and harmonization of TTMs should therefore play a key role in effortlessly developing and strengthening essential and practical competencies in vocational institutions and workplaces. This is because students' inability to think critically during internship, work in teams and effectively communicate have remained a concern in hospitality workplaces [7], [16]. Bridging the gap of TTMs in vocational institutions and workplaces in hospitality industry is becoming prerequisite and critical for teachers and trainers as they promote successful acquisition of relevant competencies [17], foster engagement and transformation [2] and successful transition of further learning [8]. 


\section{A. Teaching and training methods linkage in Uganda}

In Uganda, TTMs that foster instruction especially in vocational institutions and workplaces have gained currency in the curriculums like in other parts of the world [10]. The obligation for teachers to primarily use teaching methods that foster learning and acquisition of knowledge, essential and practical competencies are continuously emphasised [18]. The TTMs that are currently being used in vocational instutions and workplaces emphasize practical skills acquisition at the expense of essential skills. [11], [19]. Appropriate TTMs are considered as effective antidotes to authoritarian instruction practices associated with teacher dominance and passive rote learning and the stifling of critical and creative thinking [10]. According to [17] TTMs that aim to overcome authoritarian instruction practices by promoting students' participation in decision-making processes in classrooms are vital

In the workplace, on-the-job training methods are generally used to develop students' who undergo internship with relevant competencies[8], [20]. However, students strengthening of essential and practical competencies remain a challenge in workplaces despite their acquisition and development in vocational institutions. This is attributed to a purely academic education system inherited from the British colonial government designed to impart learners with majorly cognitive skills[21], [22], teacher centered methods [23], resource limitations accorded to the education sector [19], infrastructural challenges [11], crowded lecture halls, and high student-teacher ratios [17] and teacher education programs containing substantial inconsistencies of proper training and minimal opportunities for reflective practice [19], [24]. Similarly, within the hospitality industry, students undergoing internship in workplaces are presented as having skill deficits in communication, teamwork and problem-solving [11], [19], [25], [26]. This could be addressed by teachers and trainers continuously harmonizing TTMs between classroom teaching and workplace training [27]. A few studies indicated a gradual teaching transformation to instruction where students and the activities to be learnt were central in learning institutions and workplaces [8], [11], [19], [28]. However, it should also be noted that there are limited scholarly studies conducted and published on strengthening of essential and practical workplace competencies aligned with vocational institutional oriented training processes in hospitality industry. Therefore, in order to establish the harmonization and horizontal expertize of TTMs between classroom teaching and workplace training within the hospitality industry, the sought to: examine TTMs applied in hospitality training, linkage of TTMs in relation to selection and reasons for choice, planning, guidance, evaluation, reflection and follow up.

\section{B. Hospitality Program in Ugandan Context}

The three year national diploma in hotel management (NDHM) as one of the vocational education and training programs in Uganda is the focus of the study. The NDHM has got teaching methods that include group work, lectures, demonstrations, discussions, and presentations (Ministry of
Tourism and Antiquities, 2013). Students offering the NDHM program are expected to acquire functional essential and practical from the teaching methods used by teachers in order to seek new ones as well as adapt and strengthen to them during internship (Ministry of Tourism and Antiquities, 2013). Internship is a vital component of the NDHM program and takes place during the recess semester i.e. at the end of the second semester of the final academic year, and it is programmed to last for a period of ten weeks. During internship, students are expected to appreciate the importance of human relationships, attitude towards work, and selfconfidence (Kalanda, Malenya, and Otiende 2020, p. 204). Each student is supposed to be supervised by both the teacher and the trainer. The trainers at the relevant workplace, collaborate with vocational institutions to mentor the students for the duration of the training. The teacher is expected to visit students twice in the workplace during training to assess progress, performance and challenges encountered.

\section{Study Objective}

The objective of the study was to explore the linkage of teaching and training methods between classroom teaching and workplace training in the hospitality industry in Uganda.

\section{Theoretical Framework}

The study was guided by theory of expansive learning developed by Engeström in 1987 who opined a six-stage epistemic actions cyclic model[29] that includes:

\author{
Questioning \\ Analysis \\ Modeling the new solution \\ Examining and testing the new model \\ Implementing the new model \\ Reflecting on the process \\ Consolidating and generalizing the new practice
}

This six- stage epistemic actions model shapes knowledge actions and maintains that intentions, plans as well as instructional actions do not mechanically determine the course of the participants' learning [30]. These are central in understanding TTMs applied in vocational institutions and workplaces. Supported by several studies of Engeström, epistemic actions emphasize physical performance with the intent of either gathering information or facilitating cognition [30]-[32]. In addition, they are primarily identified through lengthy exchanges of discussions accompanied by gestures, postures, gazes and the use of physical artefacts (textual and graphic representations) [29], [31]. Without understanding the sequential and cyclic nature of TTMs used to develop and strengthen students' essential and practical competencies for the hospitality industry, the horizontal expertize of teaching in vocational institutions and training in workplaces can be affected. The six- stage epistemic actions model is linked to the stages of organization of TTMs that include; selection and reasons for choice, planning, guidance, evaluation, reflection and follow up. 


\section{LITERATURE REVIEW}

\section{A. Selection of Teaching and Training Methods and Reasons for Choice}

Selection of teaching methods as one of the key elements used for instruction were determined by curriculums [33], [34]. Selection of teaching methods is a valuable developmental process for any educational program including hospitality, and it is attributed to redevelopment, improving student learning, engagement, experience and outcomes[35]. Whereas [36] argued that classroom teaching methods were majorly traditional and focused on rules and expectations, studies show that teaching methods are general and have got pedagogic principles [34], [37]. These primarily fall into two categories that is, teacher-centered and student-centered [33]. Regarding, teacher-centered or teacher initiated methods, [33] proposed that teachers were the main authority figures in possession of all knowledge, expertise and guidance of the learning process while students viewed as receptors received it through lectures and direct instruction with an end goal of testing and assessment. Teacher initiated methods that majorly include lectures and question and answer are expansively useful and effective instructional strategies for facilitating essential and practical competencies among students and are strongly supported by scholars ( see [33], [34], [37]-[39]). On the other hand, [33] and [37] argued that the indirect teaching methods that include discussion, and demonstration as well as heuristic methods comprising of problem solving, discovery and project work, advocate for teachers as authority figures to coach and facilitate student learning and comprehension of material. Overall, teachers and students play an equally active role in the learning process. In the workplace training methods are dependent on the tasks assigned to students[40]. On-thejob and off-the-job training methods used by trainers/ supervisors enable students undergoing internship to conduct tasks assigned to them. According to [8], [20] examples of the on-the-job training include but are not limited to job rotations and transfers, coaching and/or mentoring. On the other hand, off-the-job training examples include conferences, role playing, and many more. Within the Ugandan context, a few studies indicated selection of teaching methods were dependent on approved curriculums by the Uganda National Council of Higher for Education [8], [11], [19], [28]. While in the workplaces training methods were dependent on the tasks assigned to students [8], [10], [28], the selection of TTMs and reasons for choice in vocational institutions and workplaces are scantly addressed and unknown.

\section{B. Planning stage}

Planning teaching methods for the classroom is dependent on the decision of what the teachers need to teach from the course[33], [41], amount of time allotted to what will be taught and activities that in order have desired outcomes during instruction[33], [34]. On the other hand [8], [20], [42] suggested that training methods for students undergoing internship in the workplace were dependent on students experiences curriculum needs, students expectations and labour market expectations. Unlike other countries, training in hospitality in Uganda is challenged by a number of issues as explained earlier [11], [17], [19], [23]. This could be contributing to skills deficits thereby affecting the bridging of the gap between vocational institutions and workplaces [26], [43] [44].

\section{Guiding stage}

The use of effective teaching methods as one of the key elements in guiding instruction during classroom teaching was vital through a planned sequence of activities[33], [34], [37]. In the workplaces, the guidance stage takes the form of close guidance, direct interaction between more experienced workers and students, the use of questioning, dialogues and group discussions aimed at assisting students to assess the scope and the limits of their knowledge and the possibilities of its transfer to new situations[40]. Similarly [45] also observed that guiding instruction could also take place through briefings, questions and answers, learning events and task delegation. Hospitality training is dependent on the teacher centered approaches which advocates for teachers as main authority figures in guidance of the learning process [28]. While in the workplace sharing of experiences between trainers and students is emphasized [8]. This could be affecting the harmonization between TTMs in vocational institutions and workplaces.

\section{Evaluation stage}

The use of teaching methods during evaluation classroom teaching being indispensable for ensuring students mastery [33] of essential and practical competencies [46]. However their effectiveness has not been fully addressed [36] especially in the hospitality industry. According to [33] mastery is demonstrated teachers need to start planning the next cycle (stage 1) or follow up methods [33], [36]. In the workplace, [12], [47] indicated that evaluation is basically a continuous on basis Similarly, in hospitality training studies haven't been conducted on evaluation processes of classroom teaching and workplace training. Therefore a need for this study.

\section{E. Reflection stage}

Whereas [33], [34], [37] argue that the use of teaching methods during the reflection stage determines whether the instruction process has accomplished its intended purpose, advocacy and criticism for this stage is not available in hospitality training. This stage needs enable the analysis and addressing the re-teaching needs if any. In the workplace reflection and follow-up processes according to [48] are concurrently and continuously. Workplace training being productivity based [45], [49], [50] argued that during the use of training methods Turing reflection were dependent to the outcomes of the tasks. They also observed that reflection processes were vital for relating tasks and activities through expected outcomes as well as encouraging and getting feedback from students for each task. With regard to hospitality training, studies haven't been conducted on reflection processes of TTMs. 


\section{F. Follow Up stage}

According to [30], [31], [33] the need to identify teaching methods that enable the summary and consolidation tasks or activities covered during instruction is vital. With regard to hospitality training, studies regarding the follow up stage of TTs haven't been conducted. Whereas [36] proposed that the extent of follow-up is dependent on the findings of the evaluation analysis, it was done in an integrated and continuous.

\section{METHODOLOGY}

\section{A. Participants of the Study}

Participants from two vocational institutions and two workplaces in Uganda were purposively selected for the study. Participants included that twelve hospitality teachers (six from each vocational institution) and four supervisors (two from each workplace) respectively as shown in table 1 . They had experience of eight to twelve years of teaching and training experience in hospitality vocational institutions and workplaces. All participants from two vocational institutions and workplaces voluntarily accepted to participate and shared their experiences to completion of the scheduled study interviews.

Table 1: Category of participants and their teaching or training experience in the hospitality industry

\begin{tabular}{|c|c|c|}
\hline $\begin{array}{c}\text { Kind of respondents } \\
\text { Remarks }\end{array}$ & Number & $\begin{array}{c}\text { Teaching/training } \\
\text { experience (years) }\end{array}$ \\
\hline $\begin{array}{c}\text { Teachers from vocational } \\
\text { institution 1 }\end{array}$ & $\mathbf{6}$ & $\mathbf{8 - 1 0}$ \\
\hline $\begin{array}{c}\text { Teacher from vocational } \\
\text { institution 2 }\end{array}$ & 6 & $8-12$ \\
\hline Trainer from workplace 1 & 2 & $8-12$ \\
\hline Trainer from workplace 2 & 2 & $8-12$ \\
\hline
\end{tabular}

\section{B. Research Design}

A qualitative research approach using a case study design with multiple units of analysis [51], [52] was preferred to provide an in-depth contextual understanding of the study under investigation. Teaching methods and training methods applied by teachers and trainers towards equipping students with essential and practical competencies for the workplace were identified as the main units of analysis. Purposive sampling was used to access 16 participants from two vocational institutions and two workplaces in order to gain deeper understanding of study [53], [54]. Primary and secondary sources were used to collect the necessary data. For primary sources, in-depth individual interview guides that consisted of both semi-structured and open-ended questions were used to conduct interviews for about 45 to 60 minutes with the majority of the participants. Interviewees voluntarily and spontaneously expressed their opinions in a comfortable manner. The responses from in-depth interviews was triangulated with data obtained from observations and document reviews help to improve the credibility and validity of the study findings [51], [52], [54]. With regard to secondary sources, comprehensive document analysis of hospitality training programs and workplace training programs was done.

\section{Data Analysis}

All interviews were conducted in English, audio recorded and later transcribed into text and read carefully as a whole to understand the participants' perceptions about the study. Key themes of selection and reasons for choice, planning, guidance, evaluation, reflection and follow up in relation to harmonize classroom teaching to workplace training were used to categorize common and recurrent patterns [55]. In line with the theory of expansive learning consisting of epistemic actions. To validate data, a comparison of findings from participants from vocational institutions and participants from workplaces showed some consistency. The findings were also partially consistent with (1) teaching methods identified in hospitality programmes [18], training methods [20], [40]. Furthermore, cross-examining of the transcribed data was done with the study participants for purposes of data reliability and validity. Reference [55] supports respondent validation as a source of ensuring in trustworthiness in qualitative data [51], [52]. To connect to theoretical validity the theory of expansive learning, epistemic actions were read and summarized to enable the logical organisation of data. To connect to ethical validity[56] approvals were obtained from the Norwegian Centre for Research Data (NSD) and the Uganda National Council for Science and Technology (UNCST) with regard to ethical considerations relevant to obtaining data from participants. Also in reporting the data confidentiality and anonymity were maintained.

\section{RESULTS}

\section{A. Selection of Teaching and Training Methods and Reasons for Choice}

A common observation was that teachers used lectures, questions and answers, demonstrations and project work as teaching methods that were approved by the hospitality programs. In contrast, tasks being practical in nature, it was observed that trainers used on-the-job training methods that included job rotations, mentoring and coaching

Based on the responses for reasons choice from the study in vocational institutions, teacher 1 said "it enables one deliver well-organized and substantial information to the large number of students at once". Teacher 5 added that "it is an excellent way of presenting background information when introducing a new topic". Teacher 8 stated that "lectures are time efficient since he is the one who plans his entire instructional period". Another teacher 12 stated "courses with less practical sessions were taught using lectures in order to stimulate students to further read on their own. Although we observed shortcomings of exhaustion during instruction. Teacher 2 said "they require to talk for 90 minutes and yet students minimally participate", teacher 4 stated "I have to stand to during instruction to ensure attentive listening". Teacher 3, said "it encourages critical thinking and participation". Teacher 6 further added that "these methods 
enable me to ensure that tasks are clearly understood and every student participates". For tasks that were practical in nature Teacher 7 explained "I use teaching methods that enable presentation of procedures and processes". Teacher 10 added that "they are useful for providing detailed information about the tasks being assigned". A common view from all teachers about project work method was that it contributed to their reflective and creative thinking. Teacher 7 added that “......... contributes to students' imagination and reasonable judgment when it comes to identifying tasks and planning ways to improve their practice. However, teacher 8 advised that "project work should reinforce what students had learnt and give them an opportunity to demonstrate innovation". However, teacher 9 noted challenges of time consuming and excessive effort required, he said "it stimulates the imagination and skill on the part of the teachers".

In contrast, responses from trainers indicated a common view of tasks being practical in nature; they trained using on-thejob training methods. Trainer 1 asserted that "they enable students acquire skills from various operations within the industry and keeps them engaged. Trainer 2 said "students are coached by particular employees in various departments who train them on a one-on-one basis to enhance their competencies". Another, trainer 3 stated "it inculcates the workplace culture and trainer 4 quickly added "mentoring improves learning through sharing experiences. Trainer 4 added that "..... enable students to move from one department to another every two weeks and exposes them to different experiences".

\section{B. Planning stage}

Regarding the planning stage, responses indicated that they planned for their teaching methods in order have the desired outcomes during instruction. It is worth noting that even though they had similar aims of ensuring that students acquired relevant and essential competencies, the planning processes for the TTMs were not similar in application. Teacher 1 said "planning for teaching methods depends on the topics to be taught from the curriculum and preparation of relevant instructional materials". Teacher 2 asserted that "teaching methods did not require any planning since it was incorporated into all the other teaching methods the curriculum. Another teacher 3 stated "planning is for students easily relate to the objectives of the tasks while teacher 6 asserted that "This is to enable students outline and discuss key points to be demonstrated. As we observed a shortage of tools, equipment and materials, teacher 6 said "the planning stage is extremely hampered by inadequate and obsolete tools and equipment as well as limited materials. While emphasizing planning for project work, teacher 4 said "several procedures are considered, including problem identification, time management, cost and resources, finding alternative ways of resolving the identified problem, evaluating the consequences of the identified solutions and applying the most appropriate process to new problems as they arose." Another teacher 7 expressed that "that planning for project work entails basic procedures relevant to the needs, interests and concerns of the task identified". Teacher 8 added that "problems are formulated into questions to guide and evaluate students work". However, teacher 10 said "I work with the students to select, describe and discuss the problems if students had difficulty understanding them. Still about project work method, teacher 12 said "the planning stage assists in locating important sources of information for the projects, organizing work plans, budgeting and later evaluating the outputs.

Whereas the trainers also planned for training for desired outcomes, their responses significantly differed indicating that there was inconsistency in confirming the existing linkage. Trainer 1 said "we ensure student rotations are prepared before they arrive for training...... rotations for reach last every two weeks to help students develop their skills at every step and feel valuable to the hospitality business". Trainer 2 stated "we plan at the beginning and towards the end of the training process to provide students with technical knowledge, assistance and support and to share experiences. To ensure planning, trainer 3 said "supervisor- student feedback is provided about assigned tasks on a day-to-day basis".

\section{Guiding stage}

Although the teachers' process of guiding students differed from trainers, findings revealed that the guiding stage was done through planned sequences. Teacher 1 expressed "I use questions during the instruction process and expect answer to introduce tasks and relate to previous lessons as well as and provided notes at the end". However, teacher 6 from another vocational institution asserted that "the inadequacy of the questioning process doesn't enable students pay attention and most of the time. Another teacher 2 stated "during the use of teaching methods, guidance is either through randomly or systematically asking questions with the aim of addressing the objectives of given tasks". Teacher 4 said "I use the guidance stage to explain the purpose of and general expectations for the outcomes of the tasks". Teacher 7 said "to ensure effective guidance during instruction, all necessary materials and equipment are made available, functional and arranged in clear view of the students to ensure an effective instruction process". Teacher 8 said "for me I decided the tasks the students take on and direct them based on the challenges they encounter while performing the activities or tasks". Teacher 9 asserted that " 1 formulate problems into questions and direct them to students to solve. Another teacher 11 asserted that "I continuously relate the outcomes of the tasks to the identified problem in order for students to find solutions". However, teacher 10 highlighted that "the necessity for patience when guiding students to think logically is fundamental". Similarly, teacher 12 asserted "I need a lot of patience to point out examples of wrong and right thinking as they occur in the process of instruction".

From the workplace findings showed that trainers used varying on-the-job training methods on a continuous basis throughout the training process to guide the students through their assigned tasks. Whereas trainer 1 said "I make duty 
rosters to rotate and brief students where and how they are expected to work from one department to another every two weeks". Trainer 4 from anther workplace said "we use duty rosters to ensure that each student is assigned tasks, brief them on the rules and how they are expected to work". Trainer 4 further said "after assigning them duty, I ensure I ask questions after they are rotated and throughout their assignment of tasks to ensure they are completed effectively". Trainer 3 asserted that "I organize mentorship programmes regularly in the form of briefings to enable students' sharing of experiences about the tasks between me and the students". Finally, trainer 4 stated that "students are directed on a oneon-one basis to provide guidance, encouragement, support, supervisor feedback and encourage dialogue to enable them to acquire the relevant competencies".

\section{Evaluation stage}

Findings indicating varying views about how teaching and training methods were used to evaluate instructed tasks were revealed. Teacher 1 expressed that "I evaluate the tasks by asking questions and expecting answers. Teacher 2 said "I assign coursework relating to the tasks or activities instructed to widen knowledge, enhance discussion, presentation and reasoning skills". Teacher 4 said "I compare the results of the students' tasks or activities at the end of the instruction process with the expected outcomes". Another teacher 5 emphasized "I review the outcomes with the students and help them draw conclusions related to the proposed solutions". In the workplaces, evaluation processes were performed on a continuous basis. Similar evaluation processes were used. Tasks being practical in nature, trainer 1 asserted "I continuously engage the students while trainer 2 stated "I ensure that they repeatedly do the task until they show mastery". Trying and failing being the essence of training, Trainer 3 expressed "I ensure students practice tasks that are not well done several times before they move to the next". The workplace being a place for students to strengthen essential and relevant competencies, Trainer 4 said "during the evaluation stage, I task students to write down the stages of every task they assigned to them on a daily basis at the end of the day then we go through them on a regular basis for feedback purposes.

\section{E. Reflection and follow up stage}

Whereas teachers and trainers indicated they allowed for reflection and follow-up processes for the instructed tasks, these stages were used simultaneously. Teacher 1 briefly mentioned "I ask questions and expect answer about key points over and over again and give students a summary of the information at the end". Teacher 2 asserted "tasks or activities are presented in a summarized form at the end of the task. Similarly, teacher 3 said "......." Another teacher 4 stated "during reflection and follow up stages for practical sessions, large objects and materials that could be seen by all students are used to attract their attention for important facts and relationships". However, teacher 6 and 10 identified a shortcoming of limited tools, equipment and materials.
Teacher 6 said "whereas reflection informs me whether results of the tasks relate to anticipated outcomes, equipment and materials are not readily available for use during instruction. Teacher 10 from the same vocational institution quickly added "This makes it difficult assess what they have learnt in order to improve where there is a gap". Still regarding these stages "teacher 5 said "I ensure students assess each conclusion done from each task or activity, eliminate the least reliable ones and reconsider the remaining ones. In the workplace, evaluation, reflection and follow-up processes were done simultaneously and still took the forms of continuous engagement of students, task repetition and reflection writing as previously explained in the evaluation stage.

\section{DISCUSSION}

\section{A. Selection of Teaching and Training Methods and Reasons for Choice}

A comparison of the findings indicated that all the teaching methods used and their selection processes of in vocational institutions significantly differed from those in workplaces. Teaching methods that fell into teacher initiated [lectures, questions and answers], indirect [demonstrations ]and heuristic [project work] were selected from approved hospitality programmes congruently recognized [33], [34] arguments of teaching methods being determined by curriculums. In workplaces, training methods that comprised of only on-the-job [job rotations, mentoring and coaching] training methods correspondingly confirmed[40] argument that used depending on the tasks assigned to students. Whether teaching methods are dependent on approved curriculums and from those of workplaces are task based, their selection should allow for effective criticism, rejection or appreciation of fundamental and integral aspects in order to harmonise and standardize the linkage of classroom teaching and workplace training.

Although findings indicated a number of reasons for the choice of specific TTMs, they showed linkage of competence nurturing, acquisition and strengthening. The identified reasons as suggested by [2], [5], [6], are charged with a substantial function of fostering essential and practical competencies for the hospitality industry. From the findings of the study benefits of TTMs linkage between vocational institutions and workplaces should be indispensable since they enable student acquisition of essential and practical competencies such as critical, reflective and creative thinking, participation, real-life hands-on and clear understanding of tasks, improving learning through sharing as well as promoting students involvement in decision making.

Like [19] highlighted that teacher initiated methods used for classroom in Uganda as still traditional, it was noted in the findings that even where they allowed for learning, minimal participation, exhaustion and neglectful listening during instruction were exhibited. Teaching methods with aspects of fostering interactive environments[8], fostering engagement 
and transformation among students [2], promoting active learning [3] need to further be boosted for better participation, attentive listening. These in turn will improve learning through sharing experiences, workplace culture, further engage and exposure students. Thus bridging the gap between education and industry in hospitality[6]. In addition, like [35] suggested, teaching methods in vocational institutions need to be revised periodically and redeveloped to for purposes of linking classroom and workplace methodologies in order to develop, improve and strengthen students' essential and practical competencies for the $21^{\text {st }}$ century.

\section{B. Planning stage}

Whereas main findings of the planning stage for TTMs was done in different ways, it was a useful phase for scheduling ways that harmonized the linkage between classroom teaching and workplace training. For teachers and trainers, planning is valuable for identification and selection of themes for instruction, establishing basic goals and objectives, careful and detailed preparation of content as well as selection of activities and tasks to be done and setting up materials, tools and equipment in order have desired outcomes as supported by [33], [34]. It is also important to note that the planning stage by teachers as disclosed in the findings is an indication of what [15] explained as standard classroom practices and that they are dependent on the decision of what needs to be taught from the course as proposed by [33], [36]. On the other hand, as highlighted by [8] further findings from trainers revealed that planning stage had a criterion used to schedule tasks. Criterions such as systematic scheduling of tasks every two weeks with the aim of allowing exploration and development of skills development and strengthening at every step is vital. Also as [40] observed, schedules are planned either at the daily, beginning or end for induction of workplace culture, sharing experiences, providing guidance and supervisor feedback and encouraging dialogue. In order to harmonize and standardize the planning stage the need for clear Horizontal expertize and collaboration is vital. Whether the teachers need to use the teaching methods that are dependent on the approved programs, their attributes should relate to those of training methods to allow for harmonization. The purpose of harmonization is to use interacted and interrelated TTMs attributes that can improve on students' experiences and expectations, meet program needs and labour market expectations.

Similar to what [2], [20] highlighted as challenges of bridging the gap between education and industry in hospitality, findings revealed that teachers are challenged with planning for the approved teaching methods due to inadequate and obsolete tools and equipment as well as limited materials. Unavailability and inadequate tools, equipment and materials if compromised, the effectiveness of teaching methods could hamper the instruction practices and issues such as teacher dominance, passive learning and the stifling of critical and creative thinking could arise.

\section{Guiding Stage}

While the main findings of the guiding stage from both the teachers and trainers showed different processes that were not harmonised, they were vital for directing instruction of tasks and activities. Comparable to what [10], [33] proposed, teachers as main authority figures in guidance of the learning process, enabled the integration of almost all methods either randomly or systematically to guide students' logical thinking and understanding of the goals, objectives as well as general expectations of the tasks during instruction. Contrary to [40]'s observation of use of questioning, dialogues and group discussions as essential ingredients of the guiding stage, findings revealed teacher initiated methods used by teachers were unsatisfactory to promote students effective participation during instruction as well as encourage teachers' expression of practicing patience when encouraging students' logical thinking. In the workplaces, most findings revealed that the trainers guidance stage took the form briefings, sharing of experiences between supervisors and students, asking questions, supervisor feedback, encouragement and dialogues with students[40], [48]. This indicated a gap of harmonization of TTMs in vocational institutions and workplaces. Therefore, in order to facilitate harmonization during the guiding stage, teaching methods that teachers play an equally active role of questioning, dialogues and group discussions should be emphasized. This will assist to students articulate tasks, encourage imaginations and ideas for discussions, judgments evaluation and criticism.

\section{Evaluation stage}

Main findings of the evaluation stage of teachers and trainers was done in different ways during instruction but it was beneficial to improving student mastery of tasks in the classroom and strengthening them in workplaces. Similar to what [33], [34], [37] suggested, the teachers used this stage to encourage and develop the use critical thinking, widen knowledge, enhance discussion, presentation and reasoning skills. Contrarily in the workplace, tasks being practical in nature, evaluation is a continuously done to ensure mastery of tasks before moving to the next, reflection and feedback of tasks assigned. In as much as TTMs do not generally show harmonization due to external forces that include approved hospitality curriculums with majorly teacher initiated methods, their attributes should play a significant role nature essential and practical competency in vocational institutions as well as effortlessly strengthen them in workplaces.

\section{E. Reflection and Follow-up Stage}

Whereas these stages were done in different ways, findings related of both stages indicated that they were done in an integrated process. Similar to [45], [49], [50] proposed, to determine the accomplishment for the intended purpose during instruction was done through briefly asking questions and expecting answers, summary of tasks, relating tasks and activities to the anticipated tasks and activities, encouraging and getting feedback from students for each task. Unlike the 
vocational institutions, reflection and follow-up in workplaces was done on a continuous basis as proposed by [40]. Also as explained earlier, the critical issue of unavailability, inadequate and obsolete tools, equipment and materials required for the effective use of teaching methods were also emphasized as challenging during this stage[19], [28]. The unavailability and inadequate tools, equipment and materials during instruction needs to be seriously addressed to ensure teachers effective use of teaching methods. This will in turn improve and nurture students' essential and practical competencies that could be beneficial for the successful transition of further learning and future development in the workplace.

\section{CONCLUSION}

The purpose of this study was to establish the linkage between teaching and training methods applied by teachers and trainers respectively, towards equipping students with essential and practical competencies for the workplace. From the findings of the study based on the stages of linking classroom teaching and workplace training (selection and reasons for choice, planning, guidance, evaluation, reflection and follow up), participants on average established that the linkage of teaching and training methods played a significant role in nurturing and strengthening of essential and practical competencies. However, the linkage was confronted with unique challenges of minimal participation due to the unsatisfactory use of teacher initiated methods, exhaustion and neglectful listening during instruction, unavailability and inadequate tools, equipment and materials.

\section{RECOMMENDATIONS}

The subsequent recommendations that are intended at improving linkage between teaching and training methods applied by teachers and trainers can be derived from this study.

1. For successful linkage of teaching methods and training methods, their selection and reasons for choice need to be allowed to evolve through systematic harmonization of the skills oriented learning processes.

2. Teacher initiated methods are inevitable for most hospitality teachers because they are dependent on the approved programs. Therefore, there is need for horizontal expertize and collaboration in order to identify attributes of teacher initiated methods that link classroom teaching to workplace training for harmonization. This will improve, nurture and strengthen on students' essential and practical competencies.

3. Teaching methods that encourage and facilitate motivation, critical thinking discussion, reflective thinking, nurture interactive environments, promote real-life, hands-on experiences and creative expression should be used to support students' further training in workplaces.
4. Availability and adequacy of up-to-date tools, equipment and materials in vocational institutions is paramount to enable teachers' use of teaching methods that facilitate effective demonstration and linkage of tasks and activities, students' knowledge and experiences.

\section{ACKNOWLEDGMENTS}

The authors would like to acknowledge the valuable contribution of the NORHED project for funding this study.

\section{REFERENCES}

[1] M. W. Johansson and M. W. Johansson, "Tracing the moving " target ' in Didaktik of vocational classroom instruction instruction," J. Curric. Stud., vol. 52, no. 6, pp. 870-883, 2020, doi: 10.1080/00220272.2020.1795270.

[2] J. M. La Lopa, Y. N. M. K. Elsayed, and M. L. Wray, "The State of Active Learning in the Hospitality Classroom," J. Hosp. Tour. Educ., vol. 30, no. 2, pp. 95-108, 2018, doi: 10.1080/10963758.2018.1436971.

[3] S. Chau and C. Cheung, "Bringing Life to Learning': A Study of Active Learning in Hospitality Education," Asia-Pacific Education Researcher, vol. 26, no. 3-4. pp. 127-136, 2017, doi: 10.1007/s40299-017-0333-6.

[4] S. Chau and C. Cheung, "Academic satisfaction with hospitality and tourism education in Macao: the influence of active learning, academic motivation, and student engagement," Asia Pacific J. Educ., vol. 38, no. 4, pp. 473-487, 2018, doi: 10.1080/02188791.2018.1500350.

[5] L. G. Sisson and A. R. Adams, "Essential hospitality management competencies: The importance of soft skills," Journal of Hospitality and Tourism Education, vol. 25, no. 3. pp. 131-145, 2013, doi: 10.1080/10963758.2013.826975.

[6] W. C. Griffin, "Hospitality faculty: are we meeting the demands of industry?," J. Teach. Travel Tour., vol. 0, no. 0, pp. 1-22, 2020, doi: 10.1080/15313220.2020.1746225

[7] J. Shi, J. Zhang, and L. A. Cai, "Active learning for an introductory tourism course - a case study," J. Teach. Travel Tour., vol. 21, no. 1, pp. 1-18, 2020, doi: $10.1080 / 15313220.2020 .1770663$.

[8] E. D. Kalanda, F. L. Malenya, and E. J. Otiende, “An Exploration of Students Workplace Learning Placements Practice of Universities in Uganda," vol. IV, no. Xi, pp. 203-211, 2020.

[9] R. Konkola, T. Tuomi-Gröhn, P. Lambert, and S. Ludvigsen, "Promoting learning and transfer between school and workplace," J. Educ. Work, vol. 20, no. 3, pp. 211-228, 2007, doi: 10.1080/13639080701464483.

[10] L. Sikoyo, "Cambridge Journal of Education Contextual challenges of implementing learner-centred pedagogy: the case of the problem-solving approach in Uganda," Taylor Fr., vol. 40, no. 3, pp. 247-263, 2010, doi: 10.1080/0305764X.2010.509315.

[11] D. Kintu, K. M. Kitainge, and A. Ferej, "Trainers 'perception of the teaching and learning approaches used for competence development in the Technical Vocational Education and Training institutions in Uganda," IOSR J. Res. Method Educ., vol. 9, no. February, pp. 8-20, 2019, doi: 10.9790/7388-0901040820.

[12] D. M. A. Baker and R. Unni., "USA and Asia Hospitality \& Tourism Students 'Perceptions and Satisfaction with Online Learning versus Traditional Face-to-Face Instruction," vol. 12, no. 2, pp. 40-54, 2018.

[13] D. J. Deming, "THE GROWING IMPORTANCE OF SOCIAL SKILLS IN THE LABOR MARKET *.”p. 37, 2017.

[14] P. Lambert, "The boundary fade away: Innovative learning as a collaboration between vocational teacher education, educational institutions and working life Helsinki organizations." Helsinki Polytechnic, Helsinki, 1999.

[15] P. Lambert, "Learning tasks producing developmental transfer," in At the boundary-zone between school and work: new possibilities 
of work-based learning, T. T.-G. \& Y. Engeström, Ed. Helsinki: Polytechnic University Press, 2001, pp. 96-147.

[16] T. Baum, A. Kralj, R. N. S. Robinson, and D. J. Solnet, "Tourism workforce research: A review, taxonomy and agenda," Ann. Tour. Res., vol. 60, pp. 1-22, 2016, doi: 10.1016/j.annals.2016.04.003.

[17] M. Ddungu-kafuluma, S. John, and S. Wanami, "The role of training philosophy in the training of quality technical teachers and instructors in Uganda," vol. 4, no. 5, pp. 580-585, 2018.

[18] Ministry of Tourism and Antiquities, "National Diploma in Hotel Management Curriciulum; National Diploma in Tourism Management Curriciulum; National Diploma in Pastry and Bakery Curriciulum," Kampala, 2013.

[19] J. C. Okware and W. Ngaka, "Rationale and challenges of technical vocational education and training in Uganda," Tech. Educ. Vocat. Train. Dev. Nations, no. October 2019, pp. 26-44, 2017, doi: 10.4018/978-1-5225-1811-2.ch002.

[20] A. Nassazi, "EFFECTS OF TRAINING ON EMPLOYEE PERFORMANCE . Evidence from Uganda," VAASAN AMMATTIKORKEAKOULU UNIVERSITY OF APPLIED SCIENCES, 2013.

[21] A. B. K. Kasozi, "The African universities capacity to participate in global higher education for supply and production: A case of Uganda," Uganda J. Educ., vol. 4, no. 2, pp. 45-63, 2003.

[22] O. H. Nakelet, I. Prossy, O. B. Bernard, E. Peter, and O. Dorothy, "Assessment of Experiential Learning and Teaching Approaches in Undergraduate Programmes at the School of Agricultural Sciences, Makerere University, Uganda," Int. J. High. Educ., vol. 6, no. 5, p. 155, 2017, doi: 10.5430/ijhe.v6n5p155.

[23] S. Bunoti, "The quality of post-secondary education in developing countries needs professional support," Cent. Educ. Innov. An Initiat. Results Dev. Inst., pp. 1-10, 2010.

[24] J. Otaala, J. S. Maani, and G. G. Bakaira, "Effectiveness of university teacher education curriculum on the secondary school teacher performance in Uganda: The case of Kyambogo University," J. Int. Coop. Educ., vol. 15, no. 3, pp. 95-112, 2013.

[25] Ministry of Education and Sports, "Private Sector Contribution to the Provision of Relvant Skills Development in Uganda: Commissioner, Private Schools and Institutions," Kampala, 2014.

[26] Ministry of Education and Sports, "THE TECHNICAL VOCATIONALEDUCATION AND TRAINING (TVET) POLICY IMPLEMENTATION GUIDELINES,” Kampala, 2019.

[27] Budget Monitoring and Accountability Unit, "Business, Technical and Vocational Training: Are the objectives being met?," Kampala, BMAU Briefing Paper 26 / 19, 2019. [Online]. Available: www.finance.go.ug.

[28] L. Muganga and P. Ssenkusu, "Teacher-Centered vs . StudentCentered," Cult. Pedagog. Inq., vol. 11, no. 2, pp. 16-40, 2019, doi: $10.18733 /$ cpi29481.

[29] Y. Engeström, Learning by Expandinding, An Activity - Theory approach to Developmental Research., 1st Ed. Helsinki: OrientaKonsultit, 1987.

[30] Y. Engeström and A. Sannino, "Studies of expansive learning Foundations, findings and future challenges - ScienceDirect," Educ. Res. Rev., vol. 5, no. 1, pp. 1-24, 2010, doi: https://doi.org/10.1016/j.edurev.2009.12.002.

[31] Y. Engeström, studies in Expansive Learning: Learning What is Not Yet there, 1st Ed. New York: Cambridge University Press, 2016.

[32] H. Engeström, Y; Kerosuo, "From workplace learning to interorganizational learning and back: The contribution of activity theory.," J. Work. Learn., vol. 19, pp. 336-342, 2007.

[33] D. K. Moore, Effective Instructional Strategies: From Theory to Practice, 4th editio. Thousand Oaks/London/ New Dheli: Sage Publications, 2014.

[34] D. R. Daniel Muijs, Effective Teching: Evidence and Practice, 3rd ed. Los Angeles/ London/ New Delhi: Sage Publications, 2011.

[35] P. Sammons, Effective teaching, no. January 2013. 2020.

[36] H. M. Egeberg, A. Mcconney, and A. Price, "Classroom Management and National Professional Standards for Teachers : A Review of the Literature on Theory and Practice," Aust. J. Teach.
Educ., vol. 41, no. 7, p. 18, 2016, doi: 10.14221/ajte.2016v41n7.1.

[37] M. Lytras and L. Daniela, Learning Strategies and Constructionism in Modern Education Settings. 2018.

[38] C. Elman, J. Gerring, and J. Mahoney, "Case Study Research: Putting the Quant Into the Qual," vol. 45, no. 3, pp. 375-391, 2016, doi: $10.1177 / 0049124116644273$.

[39] A. Y. Selcuk Kendirli, Yakup Ulker, "ACCOUNTING EDUCATION AT FACULTY OF ECONOMIC ADMINISTRATIVE SCIENCE IN KYRGYZSTAN UNIVERSITIES AND EXPECTATION OF STUDENTS FROM ACCOUNTING EDUCATION , A CASE STUDY IN BISHKEK," Res. J. Bus. Manag., vol. 2, no. 1, pp. 52-68, 2015, doi: 10.17261/Pressacademia.201519787.

[40] S. Mikkonen, L. Pylväs, H. Rintala, P. Nokelainen, and L. Postareff, "Guiding workplace learning in vocational education and training: A literature review," Empir. Res. Vocat. Educ. Train., vol. 9, no. 1, 2017, doi: 10.1186/s40461-017-0053-4.

[41] D. E. Lorenz, "Pedagogies of Resistance: Living Resistance by Writing," pp. 6-14, 2018.

[42] E. Kalanda, "Industrial Training a Workplace learning approach for Hotel trainees of Kyambogo University," Kyambogo University, 2012.

[43] J. E. Okou, "[PDF] Meeting the challenges of technical_vocational education the Ugandan experience Semantic Scholar." Ministry of education and sports, Kampala, pp. 1-11, 2002, doi: N/A.

[44] Ministry of Education and Sports, "Handbook on Polices- Acts, Policy Guidelines and Regulations," Kampala, 2011.

[45] K. Maršíková and E. Šlaichová, "Perspectives of employee training and development: methods and approachee," ACC J., vol. 21, no. 3, pp. 13-23, 2015, doi: 10.15240/tu1/004/2015-3-002.

[46] A. Thapa et al., Teacher Quality, Instructional Quality and Student Outcomes. Relationships Across Countries, Cohorts and Time (A Series of In-depth Analyses Based on Data of the International Association for the Evaluation of Educational Achievement (IEA)), vol. 52, no. 4. 2016.

[47] T. A. Kleinbort et al., "Writing in the Discipline: A Writing Mentorship Program to Enhance Student Writing Skills in the Leisure Field," Sch. A J. Leis. Stud. Recreat. Educ., vol. 35, no. 1, pp. 46-53, 2020, doi: 10.1080/1937156x.2020.1720467.

[48] T. C. M. Lam, "Training Methods: A Review and Analysis," no. April, pp. 10-35, 2016, doi: 10.1177/1534484313497947.

[49] Å. H. S. D. Bakkevig, R. J. Mykletun, and S. Einarsen, “'We're not slaves - we are actually the future!' A follow-up study of apprentices' experiences in the Norwegian hospitality industry," $J$. Vocat. Educ. Train., vol. 67, no. 4, pp. 460-481, 2015, doi: doi/full/10.1080/13636820.2015.

[50] K. Sonnenschein, M. Barker, and R. Hibbins, "Investigating higher Education Students' Professional Socialisation: a revised framework," Higher Education Research and Development, vol. 37, no. 6. pp. 1287-1301, 2018, doi: 10.1080/07294360.2018.1458286.

[51] K. Yin, R, Case Study Research. Los Angeles/ London/ New Delhi: Sage Publications Limited, 2014.

[52] B. Yazan, "Three Approaches to Case Study Methods in Education: Yin, Merriam, and Stake Three Approaches to Case Study Methods in Education : Yin , Merriam , and Stake," vol. 20, no. 2, pp. 134-152, 2015.

[53] D. Silverman, Doing Qualitative Research, 4th Ed. Los Angeles: Sage, 2014.

[54] L. Bartlet and F. Vavrus, Rethinking Case Study Resesrch: A Comparative Approach. New York: Routledge, 2017.

[55] V. Braun, V; Clarke, "Using thematic analysis in psychology," Qual. Res. Psychol., vol. 3, no. 2, pp. 77-101, 2006, doi: http://dx.doi.org/10.1191/1478088706qp063oa.

[56] E. Tuck and M. McKenzie, "Relational Validity and the 'Where' of Inquiry: Place and Land in Qualitative Research," Qualitative Inquiry, vol. 21, no. 7. pp. 633-638, 2015, doi: $10.1177 / 1077800414563809$. 